\title{
Single Versus Multiple Dose Regimen of Prophylactic Antibiotic in Cesarean
}

\section{Section}

\author{
Bhattachan K, ${ }^{1}$ Baral GN, ${ }^{2}$ Gauchan $\mathrm{L}^{3}$ \\ ${ }^{1}$ Department of Obstetrics and Gynecology, Kathmandu Model Hospital, \\ ${ }^{2}$ Department of Obstetrics and Gynecology and ${ }^{3}$ Department of Pathology, \\ Paropakar Maternity and Women's Hospital, Kathmandu, Nepal.
}

\begin{abstract}
Aims: The purpose of this study was to compare the efficacy of single combined dose of Cefotaxime and Metronidazole against conventional regimen of Ampicllin and Metronidazole for five days for the prevention of infectious morbidities in cesarean deliveries.
\end{abstract}

Methods: This study was carried out at Paropakar Maternity and Women's Hospital, Kathmandu from April to August 2011. Hundred patients, who had cesarean deliveries for various indications, were divided into two groups with fifty on each arm. Patients in group I were treated with intravenous single dose of Cefotaxime and Metronidazole after cord clamping, whereas those patients in group II were treated with Ampicillin and Metronidazole for five days. Efficacy of the treatment was compared in terms of postoperative infectious morbidities, duration of hospital stay and cost of antibiotics.

Results: Overall ten cases (10\%) had post-operative complications in which eight ( $8 \%$ ) had infectious and two (2\%) had thrombophlebitis. The infectious morbidities were febrile morbidities in four cases $(4 \%)$ followed by urinary tract infection in three cases $(3 \%)$ and wound infection in one case (1\%). There was no statistically significant difference among distribution of these morbidities and in the mean duration hospital stay. The cost of single dose regimen was one-eighth of the multiple dose regimens which was statistically significant $(\mathrm{p}=0.000)$.

Conclusions: Single dose of Cefotaxime and Metronidazole was equally effective as multiple doses of Ampicllin and Metronidazole for five days in prevention of infectious morbidities with benefit of cost.

Keywords: cesarean section, infectious morbidities, prophylactic antibiotic.

\section{INTRODUCTION}

Cesarean delivery is defined as the birth of a fetus through incision in the abdominal wall and the uterine wall. ${ }^{1}$ It is an essential and most commonly performed surgery whose prevalence is increasing each year. Obviously there will be increasing surgery related morbidities. Infectious complications following cesarean delivery include febrile morbidity, endometritis, wound infection and urinary tract infection. There can be occasionally more serious complications like pelvic abscess, peritonitis, bacteremia, septicemia, necrotizing fasciitis, burst abdomen, and septic pelvic vein thrombophlebitis. ${ }^{2}$ There are various interventions to minimize such morbidities like aseptic technique, antibiotic prophylaxis and surgical expertise. Though

\section{CORRESPONDENCE}

Dr Kabin Bhattachan

Department of Obstetrics and Gynecology,

Kathmandu Model Hospital, Pradarshani Marg,

Kathmandu, Nepal.

E-mail: kabin_b@hotmail.com

Phone: +977-9851063726 routine prophylactic antibiotic has been proven to be efficacious in reducing these morbidities, ${ }^{3}$ but there is still debate about the choice of antibiotic, time of administration, doses and duration of its uses. Single dose antibiotic are recommended for cesarean delivery, ${ }^{1}$ but there is still a tendency to use multiple drugs for long duration. Therefore it is a prime time to decide on appropriate and cost effective measures especially in a resource limited country like Nepal. The purpose of this study was to compare the efficacy of single combined dose of Cefotaxime and Metronidazole against conventional regimen of Ampicllin and Metronidazole for five days in terms of prevention of infectious morbidities, mean duration of hospital stay and cost of antibiotic in cesarean deliveries.

The papers in this journal are published under the terms of the Creative Commons Attribution License. Users are allowed to read, download, copy, distribute, print, search, or link to the full texts of the articles in this journal without asking prior permission from the publisher or the author 


\section{METHODS}

This study was done at Paropakar Maternity and Women's Hospital during five months period from April to August 2011. The study was started only after taking permission from the hospital authority. All the women included in the study were informed about various aspects of the study and informed consent was taken. The inclusion criteria were those cases undergone for elective and emergency cesarean section at term irrespective of age and parity. The exclusion criteria were cases with added risk for infection like; pre-existing febrile illness, premature rupture of membrane, prolonged or obstructed labor, moderate to severe anemia, postpartum hemorrhage, and manual removal of placenta.

Both elective and emergency caesarean section cases meeting the set criteria were enrolled in the study. Study populations were numbered serially from the beginning of the study. First case taken from the day of data collection was enrolled as study group (group I) and the every other cases were enrolled into control group (group II). In place of cases that were excluded due to post-partum hemorrhage and manual removal of placenta were replaced by new cases immediately. Patients in group I were treated with intravenous intraoperative single combined dose of Cefotaxime $1 \mathrm{gm}$ plus Metronidazole $500 \mathrm{mg}$ stat after cord clamping and no more doses of antibiotic were given to this group. Patients in group II were treated with conventional regimen of antibiotic of Ampicillin 2 gm plus Metronidazole $500 \mathrm{mg}$ intravenously after cord clamping followed by maintenance therapy as Ampicillin $1 \mathrm{gm}$ six hourly and Metronidazole 500 mg eight hourly intravenous for 24 hours and they were switched over to oral for four more days. Foley catheter and IV cannula were removed after 24 hours. Post-operative fever, features suggesting of urinary tract infection and signs of endometritis like fever, tender uterus and abnormal foul smelling lochia were noted. Mid-stream urine was sent on third postoperative day for routine examination. Incision site was inspected on day third for signs of infection. All the enrolled cases were followed up throughout their hospital stay. Those patients who were well on day four were discharged. Every patient were instructed to report to the hospital at any time whenever they developed problems like fever, foul smelling vaginal discharge or bleeding, discharge from the wound margin, and breast engorgement within two week of discharge or to come to the hospital for follow up at two weeks. The patients who could not come for follow up were traced by telephone. Data were entered in a SPSS excel spread-sheet. Data analyses were made manually as well as with a help of the computer using SPSS program. Appropriate statistical tests (like Fisher's exact test, Student's $t$ test) were carried out for testing the significance. $\mathrm{P}$ value is considered significant if it is $<0.05$.

\section{RESULTS}

Hundred patients meeting the set criteria who underwent cesarean section either as an emergency or elective basis had participated in this study with fifty on each arm. There were four cases of postpartum hemorrhage and two cases of manual removal of placenta, all of them were excluded from the study analysis and were replaced by new cases immediately. There is homogeneity among the study population in terms of their demographic characteristics such as age, parity, gestational age and type of cesarean section.

\begin{tabular}{|c|c|c|c|c|}
\hline Characteristics & $\begin{array}{l}\text { Group I } \\
\text { N (\%) }\end{array}$ & $\begin{array}{l}\text { Group II } \\
\text { N (\%) }\end{array}$ & Total & $\begin{array}{l}\text { p } \\
\text { value }\end{array}$ \\
\hline \multicolumn{5}{|l|}{ Age (years) } \\
\hline$<25$ & $28(56)$ & $27(54)$ & 55 & 1.000 \\
\hline $25-34$ & $20(40)$ & $20(40)$ & 40 & \\
\hline$>35$ & $2(4)$ & $3(6)$ & 5 & \\
\hline Mean \pm SD & $24.58 \pm 4.43$ & $24.90 \pm 4.87$ & & \\
\hline \multicolumn{5}{|l|}{ Parity } \\
\hline Primi & $24(48)$ & $24(48)$ & 48 & 1.000 \\
\hline Multi & $26(52)$ & $26(52)$ & 52 & \\
\hline \multicolumn{5}{|l|}{ Gestational age } \\
\hline 37-40 week & $38(76)$ & $35(70)$ & 73 & 0.251 \\
\hline 41-42 week & $10(20)$ & $14(28)$ & 24 & \\
\hline$>43$ week & $2(4)$ & $1(2)$ & 3 & \\
\hline \multicolumn{5}{|l|}{ Type of CS } \\
\hline Elective & $21(42)$ & $16(32)$ & 37 & 0.408 \\
\hline Emergency & $29(58)$ & $34(68)$ & 63 & \\
\hline
\end{tabular}

The main indications for cesarean section were fetal distress, previous cesarean section followed by breech presentation and cephalo-pelvic disproportion.

\begin{tabular}{|c|c|c|c|c|}
\hline Morbidities & $\begin{array}{l}\text { Group } \\
\text { I } \\
\text { N (\%) }\end{array}$ & $\begin{array}{l}\text { Group } \\
\text { II } \\
\text { N (\%) }\end{array}$ & $\begin{array}{l}\text { Total } \\
\text { N }\end{array}$ & $\begin{array}{l}P \quad- \\
\text { value }\end{array}$ \\
\hline $\begin{array}{l}\text { Febrile } \\
\text { morbidities }\end{array}$ & $1(2)$ & $3(6)$ & 4 & 0.617 \\
\hline UTI & $2(4)$ & $1(2)$ & 3 & 1.00 \\
\hline Wound infection & $1(2)$ & 0 & 1 & 1.00 \\
\hline Thrombophlebitis & 0 & $2(4)$ & 2 & 0.495 \\
\hline Total & $4(8)$ & $6(12)$ & 10 & \\
\hline
\end{tabular}




\begin{tabular}{llll}
$\begin{array}{l}\text { Table 3. Distribution } \\
\text { (n=100). }\end{array}$ & Infectious & morbidities \\
\hline Indication & $\begin{array}{l}\text { Group I } \\
\text { N (\%) }\end{array}$ & $\begin{array}{l}\text { Group II } \\
\text { N }(\%)\end{array}$ & Total N \\
\hline $\begin{array}{l}\text { Fetal } \\
\text { distress }\end{array}$ & $11(22)$ & $23(46)$ & 34 \\
Previous CS & $16(32)$ & $5(10)$ & 21 \\
Breech & $8(16)$ & $7(14)$ & 15 \\
presentation & & & \\
CPD & $6(12)$ & $5(10)$ & 11 \\
IUGR & $3(6)$ & $2(4)$ & 5 \\
Others & $6(12)$ & $8(16)$ & 14 \\
\hline
\end{tabular}

The common post-operative complications were febrile illness and urinary tract infection, followed by thrombophlebitis and wound infection. Though there was uneven distribution of morbidities, it was not statistically significant.

\begin{tabular}{|c|c|c|c|}
\hline $\begin{array}{l}\text { Duration } \\
\text { of hospital } \\
\text { stay }\end{array}$ & Group I & Group II & P-value \\
\hline$\leq 1$ week & 49 & 48 & \\
\hline$>1$ week & 1 & 2 & \\
\hline $\begin{array}{l}\text { Mean } \\
\text { duration } \\
\text { (days) }\end{array}$ & 4.40 & 4.42 & 1.000 \\
\hline
\end{tabular}

There was no statistical difference in the mean duration of hospital stay.

\section{DISCUSSION}

In this study there was homogeneity among the groups in regards to their demographic characteristics. Out of total CS, 63\% had emergency and remaining 37\% had planned surgery. The main indications for cesarean section were fetal distress, previous CS, followed by breech presentation and CPD (Table 2). Eight cases $(8 \%)$ had infectious complications in our study. This finding is comparable to a study by Shakya et $\mathrm{al}^{4}$ in which $7 \%$ had post-operative infectious morbidities. In a study of Denmark among 32,468 mothers, the overall infectious morbidities was $7.6 \%$ in $\mathrm{CS}$ when compared to $1.6 \%$ in vaginal delivery. ${ }^{5}$ And similar results were obtained in the study of Ziogos et $\mathrm{al}^{6}$ and Shetty et $\mathrm{al}^{7}$ in which overall infectious morbidities were $7.4 \%$ and $7.3 \%$ respectively. In our study, there were two cases of thrombophlebitis at IV site in group II but this complication was not seen in group I.

\section{Febrile morbidity}

In our study four cases (4\%) developed postoperative febrile illness. None of these cases had any signs and symptoms of underlying focal or systemic illness. These findings were comparable to the study of Shakya et $\mathrm{al}^{4}{ }^{4}$ Ahmed et $\mathrm{al}^{8}$ and Alekwe et $\mathrm{al}^{9}$ in which the post-operative febrile morbidities were $5 \%, 6.5 \%$ and $6.5 \%$ respectively.

\section{Surgical wound infection}

Wound infection is one of the most common complications occurring following any surgery. The incidence of wound infection following cesarean delivery ranges from $3 \%$ to $15 \%$ with an average of $6 \% .{ }^{10}$ Moreover it prolongs the hospital stay, increases cost, and work load. In our study only one $(1 \%)$ case in group I had wound infection. This finding is comparable to finding of William et $\mathrm{al}^{11}$ and Shetty et al ${ }^{7}$ in which the wound infection rate were $1.5 \%$ and $1.6 \%$ respectively. Kahyihura et $\mathrm{al}^{12}$ did a study in Mozambique comparing single dose versus existing policy of administering multiple dose regimen for seven days. However, that study showed $5.8 \%$ of wound infection with no statistically significant difference.

\section{Urinary tract infection}

Urinary tract infection is common infectious morbidity following cesarean delivery. Multiple pervaginal examination, frequent urinary catheterization and failure to maintain aseptic technique during catheterization, bladder trauma and occult bacteriuria are risk factors for development of post-operative urinary tract infection. ${ }^{13}$ Three cases $(3 \%)$; two in the study group and one in the control group had urinary tract infection detected either by symptoms or on routine examination of urine. This finding is comparable to study of William et al, ${ }^{11}$ Shakya et al ${ }^{4}$ and Shetty et $\mathrm{al}^{7}$ in which incidence of urinary tract infections were $3.5 \%, 2 \%$ and $2.4 \%$ respectively.

\section{Duration of hospital stay}

Hospital stay is a matter of concern for every patient and their family. Moreover when the hospital stay is prolonged due to infectious complication, it is associated with psychological upset. The mean duration of hospital stay in our study was 4.40 and 4.42 days for group 1 and 2 respectively $(p=1.00)$. There were no cases of re-hospitalization on either group during the follow up period. This finding is comparable to study of Kayihura et $\mathrm{al}^{12}$ in which the mean duration of hospital stay was 3.3 days and 3.6 days respectively in study and control group and the study of Ziogos et $\mathrm{al}^{6}$ in which the mean duration of hospital stay was four days.

\section{Treatment cost}

Cost is the matter of issue and concern especially in developing countries like Nepal where the patients' themslves have to bear all the cost. If single dose of 
any antibiotic is equally effective as multiple drugs doses, then it is irrational to use multiple drugs for long period. The mean cost of antibiotic in the study group was Nepalese rupees 90.12 (\$1.2) when compared to 722.48 rupees $(\$ 9.6)$ in the control group. This means single dose regimen costs one eighth of the multiple dose regimen, which is statistically significant $(\mathrm{p}=$ 0.0001). This finding is comparable to cost benefit study done by Kayihura et $\mathrm{al}^{12}$ which also concluded that single dose regimen costs one tenth of the multiple drug doses for week long therapy with equal potency. Similarly, Alekwe et $\mathrm{al}^{9}$ compared the cost of single dose regimen of Ceftiraxone with multiple doses of Ampicillin, Gentamicin and Metronidazole for seven days therapy as prophylaxis and they concluded that single dose regimen is equally effective in reducing post-operative infectious morbidities with benefit of significant reduction in cost.

\section{CONCLUSIONS}

Single dose regimen with Cefotaxime and Metronidazole as a prophylaxis during cesarean section against multiple dose regimen of Ampicillin and Metronidazole for five days as a usual hospital practice was equally effective in preventing surgical infectious morbidities with no difference in mean duration of hospital stay. Mean cost of antibiotic in single dose regimen was one-eighth of multiple dose regimen. Therefore there is a need of change in our practice and thereby development of a hospital protocol with emphasis on single dose of prophylaxis in cesarean delivery.

\section{REFERENCES}

1. Cunningham FG. Cesarean delivery and peripartum hysterectomy. In: Leveno KJ, Bloom SL, Hauth JC, Gilstrap LC, Wenstrom KD, editors. William's obstetrics. 22nd ed. New York: McGraw Hill; 2005. p. 588-604.

2. Boggess KA, Watts DH, Hiller SL, Krohn MA, Benedetti TJ, Eschenbach DA. Bacteremia shortly after placental separation during cesarean section. Obstet Gynecol. 1996;87:322-4.
3. Mugford M, Kingston J, Chalmers I. Reducing the incidence of infection after cesarean section: implications of prophylaxis with antibiotics for hospital resources. BMJ. 1989;299:1003-6.

4. Shakya A, Sharma J. Comparison of single versus multiple doses of antibiotic prophylaxis in reducing postelective cesarean section infectious morbidity. KUMJ. 2010;8:30:179-84.

5. Leth RA, Møller JK, Thomsen RW, Uldbjerg N, Nørgaard M. Risk of selected postpartum infections after cesarean section compared with vaginal birth: a five-year cohort study of 32,468 women. Acta Obstet Gynecol Scand. 2009;88(9):976-83.

6. Ziogos E, Tsiodras S, Matlliotakis I, Giamarellou H, Kanellakopoulou K. Ampicillin/Sulbactam versus Cefuroxime as antimicrobial prophylaxis for cesarean delivery: a randomized study. BMC Infectious Disease. 2010;10:341.

7. Shetty J, Rajshekhar S, Kamath A. Short term antibiotic prophylaxis for emergency cesarean delivery: is there a difference? The Internet J Gynecol Obstet. 2009; Vol 11 Number 1.

8. Ahmed ET, Mirghani OA, Gerais AS, Adam I. Ceftriaxone versus Ampicillin/Cloxacillin as antibiotic prophylaxis in elective cesarean section. Eastern Mediterr Health J. 2004; 10:277-82.

9. Alekwe LO, Kuti O, Orji EO, Oqunniyi SO. Comparison of Ceftriaxone vs. triple drug regimen in the prevention of cesarean section infectious morbidities. J Maternal Fetal and Neonatal Med. 2008;21(9):638-42.

10. Owen J, Andrews WW. Wound complications after cesarean sections. Clin Obstet Gynecol. 1994;37:842.

11. Wiiliam WK, Winnie NT. A protocol of selective antibiotic prophylaxis for cesarean section based on risk factors. Aust N Z J Obstet Gynecol. 2001;41(4):402.

12. Kayihura V, Oamn NB, Bugalho A, Bergstrom S. Choice of antibiotic for infection prophylaxis in emergency cesarean sections in low-income countries: a cost-benefit study in Mozambique. Acta Obstet Gynecol Scand. 2003;82:636-41.

13. Steer JP. Puerperal sepsis. In: Chamberlain G, Steer P, editors. Turnbull's obstetrics. 3rd ed. London: Churchill Livingstone; 2001. p. 663-7. 